\title{
"Mucin secreting" and "mucinous" primary thyroid carcinomas: pitfalls in mucin histochemistry applied to thyroid tumours
}

\author{
C RIGAUD, W V BOGOMOLETZ \\ From the Laboratoire d'Anatomie Pathologique, Institut Jean Godinot, Reims, France
}

SUMMARY Forty primary carcinomas of the thyroid of different histological types were reviewed and studied histochemically, with the aim of identifying and assessing "mucin secretion". The patterns of extracellular "pure alcianophilia" and "mixed alcianophilia" were noted in $7 \cdot 5 \%$ and about $50 \%$ of these tumours, respectively. A critical review of the pitfalls in methods and interpretation of mucin histochemistry-as performed in previously reported cases of "mucin secreting" or "mucinous" primary thyroid tumours-is presented. The apparent "mucin secretion" described in these unusual neoplasms could be due to histochemical staining of carbohydrate components or breakdown products of thyroglobulin and colloid.

Cases of "mucin secreting" or "mucinous" primary carcinomas and adenomas of the thyroid have been increasingly reported in the past decade. ${ }^{1-19}$ The diagnosis of "mucin secretion" in these unusual thyroid tumours has essentially relied on the apparent positivity of different histochemical methods for mucins. These methods are more conventionally used for the study of epithelial mucins secreted by goblet cells of the gastrointestinal or bronchial tract. The major implication of these reports ${ }^{1-19}$ has been that the follicular and parafollicular cells of the thyroidan exclusive endocrine gland, by definition-could also produce "mucins" in primary tumours, in a manner similar to that of epithelial goblet cells in exocrine organs. Does conventional mucin histochemistry applied to thyroid tumours actually identify substances, which could be regarded as being equivalent to gastrointestinal and bronchial mucins, or, alternatively, show up components or breakdown products of thyroglobulin and colloid? ${ }^{2}$

In an effort to clarify further the nature of these so called "mucin secreting" or "mucinous" primary thyroid tumours we carried out a histochemical study on 40 primary carcinomas of the thyroid, using two combined staining methods for mucin identification.

Accepted for publication 26 March 1987

\section{Material and methods}

The original haematoxylin and eosin stained slides of 40 primary carcinomas of thyroid were retrieved from our files and reviewed. These 40 cases were classified according to current histological nomenclatures ${ }^{20} 21$ and included 22 papillary, nine follicular, five anaplastic, and four medullary carcinomas. All the material had been fixed in formol saline (pH 7). The paraffin blocks of these $\mathbf{4 0}$ cases were recut and numerous additional sections stained by two combined histochemical methods for mucins:

1 Alcian blue ( $\mathrm{pH} \mathrm{2 \cdot 5)}$ and periodic acid Schiff after diastase digestion (AB/PAS), which distinguishes between acidic mucins stained blue by $\mathrm{AB}$ and neutral mucins stained magenta by PAS (mixtures of acidic and neutral mucins produce a purple colour).

2 High iron diamine and alcian blue $\mathrm{pH} 2.5$ (HID/AB), which differentiates sulphomucins stained brownish black by HID and sialomucins stained blue by $\mathrm{AB}$.

These two combined histochemical methods were performed in batches, with adequate positive and negative controls, and strictly in accordance with the methods recommended by Filipe and Lake. ${ }^{22}$ We have been using this in our laboratory for many years with consistent, reproducible, and reliable results.

In this study the term "alcianophilia" was defined as any positive blue staining reaction (extracellular or intracellular) caused by the $\mathrm{AB}$ component of 
$\mathrm{AB} / \mathrm{PAS}$ or HID/AB, and regardless of the presumed nature of the stained material.

\section{Results}

Three different staining and morphological patterns could be observed in the sections of the 40 primary thyroid carcinomas: "pure", "mixed", and "foreign".

\section{PURE ALCIANOPHILIA}

This was characterised by the presence of focal extracellular material, contained within scattered neoplastic microfollicles, and showing a positive and homogeneous blue staining with both AB/PAS and HID/AB. Apart from alcianophilia, no other staining reaction was obtained with either the PAS or the HID sequences of the two combined histochemical techniques. This pattern of pure alcianophilia was identified in only three $(7.5 \%)$ of the 40 thyroid carcinomas studied-one follicular and two medullary carcinomas (fig 1).

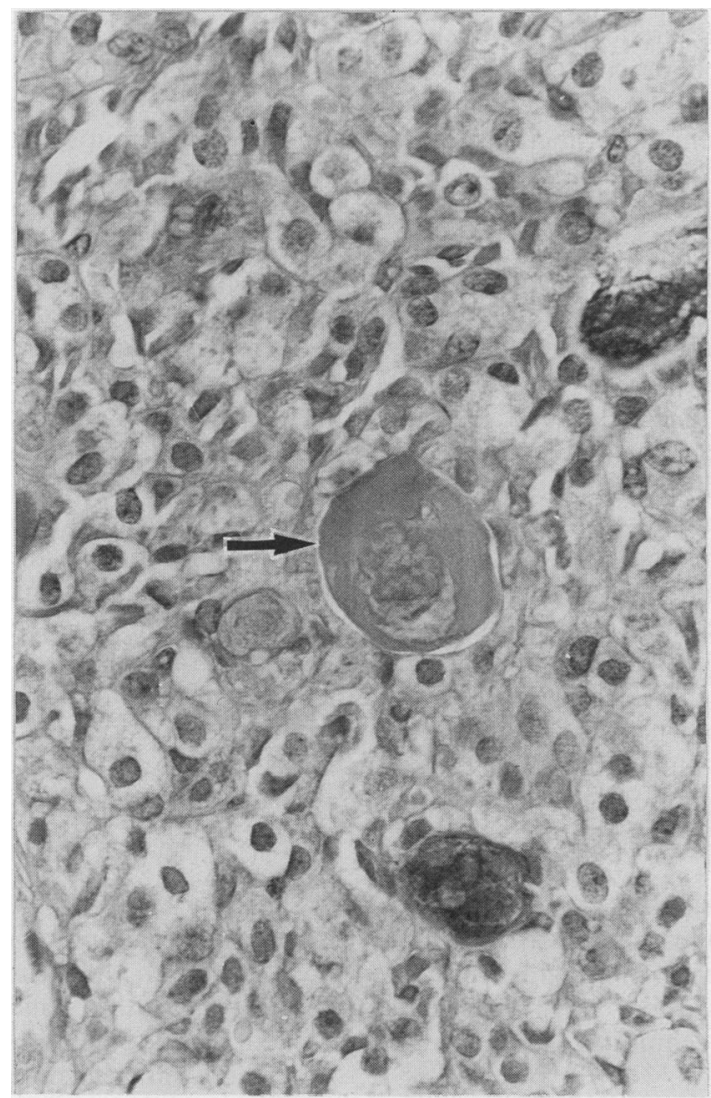

Fig 1 Medullary carcinoma of thyroid. Focal pure alcianophilia within one microfollicle (arrowed). (Combined alcian blue, $\mathrm{pH} 2 \cdot 5$, and periodic acid Schiff.)
MIXED ALCIANOPHILIA

This was characterised by the presence of focal extracellular material contained in the "colloid" of neoplastic macrofollicles and showing a positive but heterogeneous staining with both AB/PAS (admixed blue and magenta positive staining) and HID/AB (admixed brownish black and blue positive staining) (figs 2 and 3). This pattern of mixed alcianophilia was seen in about $50 \%$ of the 40 tumours, more commonly in follicular and papillary carcinomas.

\section{FOREIGN ALCIANOPHILIA}

This was characterised by a positive blue staining, obtained with both AB/PAS and HID/AB, of different tissue structures other than the intralumenal contents of either thyroid macrofollicles or microfollicles.

The extracellular material of both pure and mixed alcianophilia was scarce and scattered. Numerous sections stained by AB/PAS and HID/AB had to be carefully studied to identify positive stained material

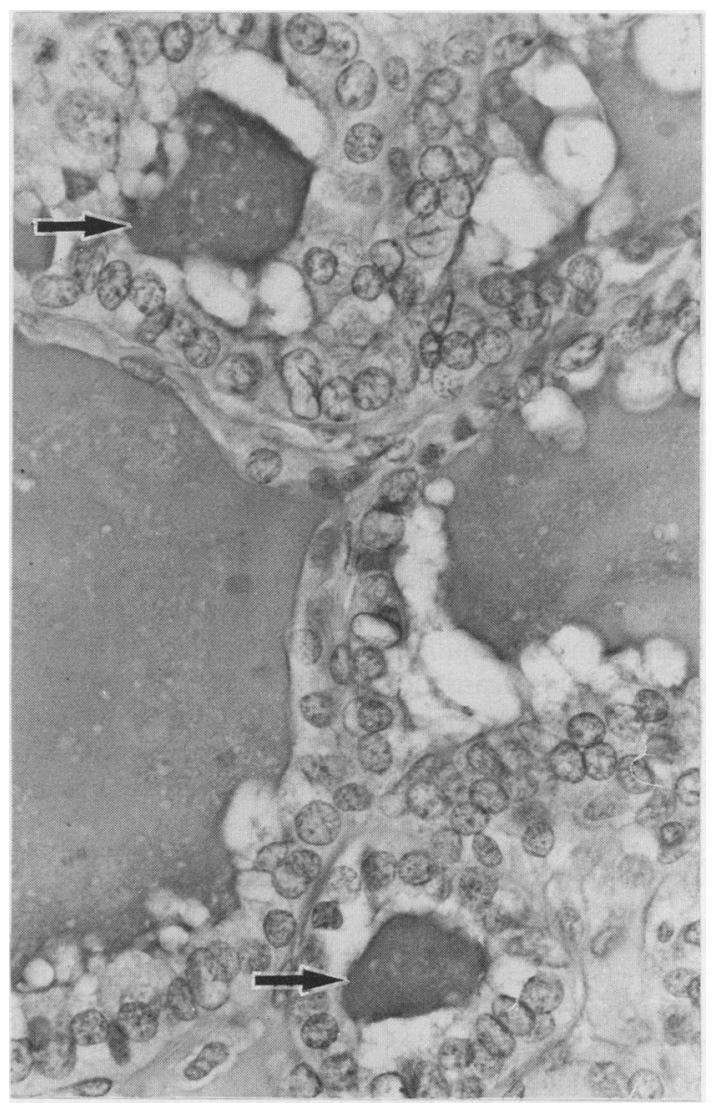

Fig 2 Follicular carcinoma of thyroid. Focal mixed alcianophilia with two macrofollicles (arrowed). (Combined high iron diamine and alcian blue, $\mathrm{pH} 2 \cdot 5$.) 


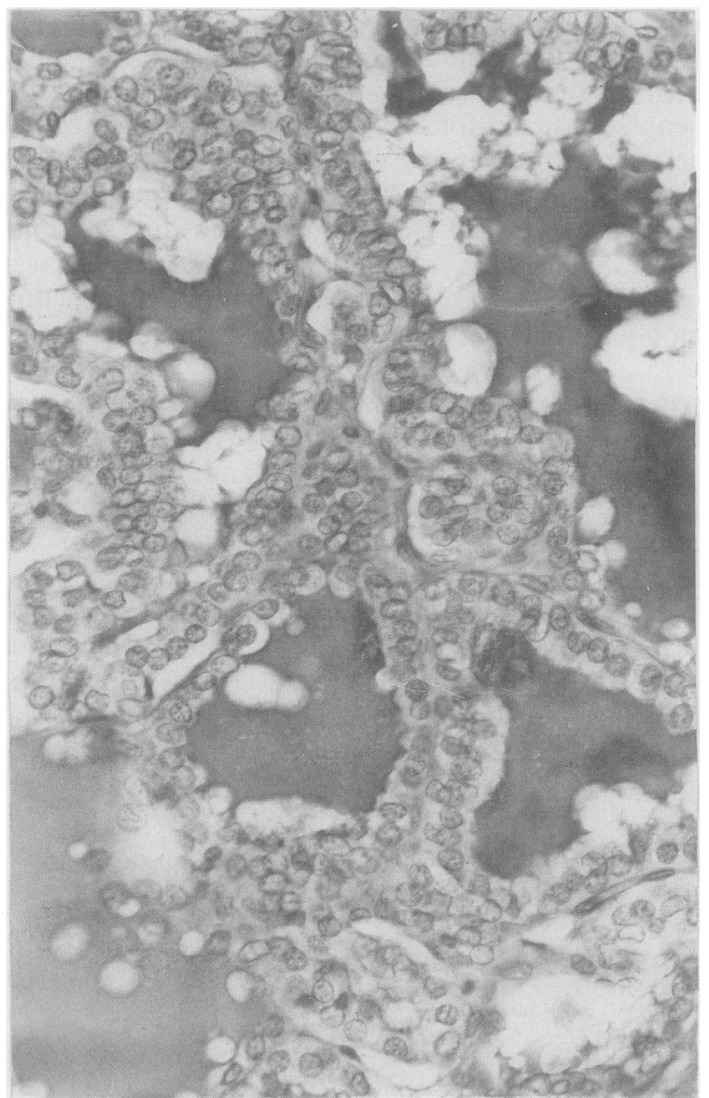

Fig 3 Papillary carcinoma of thyroid. Focal mixed alcianophilia within several macrofollicles. (Combined high iron diamine and alcian blue, $\mathrm{pH} 2.5$.)

in each case. No convincing intracellular materialAB positive, PAS positive (after diastase digestion), or HID positive - could be shown.

Foreign alcianophilia was mostly confined to the microcalcifications and the connective tissue papillae in all of the 22 papillary carcinomas $(55 \%)$. Foreign alcianophilia, caused by the $\mathrm{AB}$ staining of the glycoconjugates of interstitial connective tissue, could be abolished by prior enzyme digestion with hyaluronidase, ${ }^{22}$ and did not interfere with our study.

\section{Discussion}

An increasing number of articles on "mucin secreting" or "mucinous" primary tumours of the thyroid have been published in the past decade. ${ }^{1-19}$ These have consisted mainly of single case reports and a few series, which have included primary carcinomas of follicular and parafollicular origin, as well as benign adenomas. These unusual thyroid tumours have been variously described as "mucinous adenocarcinoma", ${ }^{3}$ "mucinous carcinoma", 51719 "mucoepidermoid carcinoma", 4101214 "mucin producing medullary carcinoma", 126-81318 "clear cell variant of thyroid carcinoma with mucin secretion", " "follicular, papillary, medullary and anaplastic carcinomas with mucinous substances", ${ }^{15}$ and "mucin producing microfollicular adenoma with signet ring cell pattern". ${ }^{1116}$ Other articles, however, have expressed contradictory opinions on the presence or absence of mucin secretion in primary thyroid tumours. ${ }^{23-25}$ In all the above reports the diagnosis of "mucin secretion" in these unusual neoplasms has relied on the apparent positivity of different histochemical methods, the latter more often conventionally used for the study of epithelial mucins produced by goblet cells of the gastrointestinal or bronchial tract.

A brief reminder of the histochemical classification of epithelial mucins is pertinent. Epithelial mucins secreted by goblet cells lining the gastrointestinal tract, bronchus, or endocervix are complex mucus glycoproteins of high molecular weight. ${ }^{218}$ Mucins are formed by a central protein core, to which different carbohydrates are attached, in the form of oligosaccharide side chains. These carbohydrates $(70$ to $90 \%$ by weight of mucins), vary in composition, length, branching, acidity and reactive groups. In effect the various histochemical methods used for epithelial mucin identification react directly with these carbohydrates. Depending on the type of carbohydrates present, epithelial mucins are classified histochemically into two broad groups-namely, acidic and neutral mucins. ${ }^{22} 2829$ Acidic mucins are divided into sialomucins (with carbohydrates containing sialic acid) and sulphomucins (with carbohydrates containing sulphate reactive groups). Enzyme digestion by sialidase may further subdivide sialomucins into sialidase labile $(\mathrm{N}$-acetyl) and sialidase resistant (O-acetyl) sialomucins. Sulphomucins are either strongly or weakly sulphated. Neutral mucins contain free hexoses but are devoid of acidic reactive groups, such as sialic acid or sulphate radicals.

At least two types of difficulties are encountered when reviewing previously published reports on "mucin secreting" or "mucinous" primary thyroid tumours 1-1823-25: problems of methods and of interpretation.

\section{PROBLEMS OF METHODOLOGY}

Various histochemical methods for showing the presence of mucins have been used, although different authors have not necessarily performed the same techniques. The PAS reaction used singly, ${ }^{124-79111215-171923-25}$ the mucicarmine technique, ${ }^{3-68-121415171923-25}$ and the copper phthalocyanin basic dye alcian blue (AB) used singly 1271214161724 have been the most popular. 
Colloidal iron has been used in two reports. ${ }^{1125}$ Two other basic dyes, astra blue and alcian green (a mixture of $\mathrm{AB}$ and alcian yellow), have each been applied on one occasion. ${ }^{1525}$ Some authors have used the combined histochemical method of AB/PAS. ${ }^{1013141618} \mathrm{HID} / \mathrm{AB}$, sialidase digestion followed by $\mathrm{AB}$ (Sial-AB), and the periodic acidsodium borohydride saponification/periodic acid Schiff reaction (PB/KOH/PAS) have only been used once. ${ }^{16}$

Precise information about certain crucial aspects or steps of these histochemical methods has been lacking in some of the above papers, particularly the type of fixative used ${ }^{1-511} 1517-1923-25$ and the $\mathrm{pH}$ of the AB solutions, the latter used singly or in combination with PAS. ${ }^{12917-19}$ Prompt and optimal fixation is important for showing the presence of epithelial mucins; acqueous formalin fixatives are satisfactory 228 and certainly less deleterious for glycoproteins than picric acid fixatives. The specific affinity of the carboxyl and sulphate groups acidic mucins for $A B$ and the resulting staining intensity shown in tissue sections depend on full ionisation of these reactive groups, hence on the $\mathrm{pH}$ used. At $\mathrm{pH}$ $2 \cdot 5$, sialidase labile sialomucins and weakly sulphated sulphomucins will stain well with $\mathrm{AB}$, but sialidase resistant sialomucins and strongly sulphated sulphomucins will react better with $\mathrm{AB}$ at a lower $\mathrm{pH}(1.0$ and $1 \cdot 5$, respectively). ${ }^{28}$ When PAS was used singly, authors did not always make it clear whether prior digestion with diastase had been carried out to eliminate glycogen. ${ }^{121215}$ Used singly, PAS is a useful general but non-specific indicator of epithelial mucins in tissues. PAS will react positively with neutral mucins and sialidase labile sialomucins, but negatively with sialidase resistant sialomucins; furthermore, PAS will give a variable staining reaction with weakly sulphated sulphomucins. ${ }^{22} 2829$

As mentioned earlier, mucicarmine has been extensively used in most reports on "mucin secreting" and "mucinous" primary tumours of the thyroid. Mucicarmine, however, will stain some but not all mucins. ${ }^{2829}$ Sialomucins and weakly sulphated sulphomucins give positive results with mucicarmine, but neutral mucins and strongly sulphated sulphomucins tend to be negative with this stain. Recently, Cook questioned if mucicarmine had a real place in the contemporary armamentrium of histochemical methods for mucins. ${ }^{28} \mathrm{He}$ also suggested that the combined AB/PAS technique, "will establish the presence or absence of tissue mucins more certainly and more informatively" (than mucicarmine). Furthermore, Drury and Wallington ${ }^{29}$ pointed out that the preparation of an optimally avid mucicarmine staining solution is difficult and may vary, depending on batches; commercial mucicarmine tends to be less satisfactory than mucicarmine prepared in the labora- tory. The pitfalls of mucicarmine staining are exemplified by the negative findings of two earlier and often cited studies on "mucin secreting" or "mucinous" primary thyroid carcinomas. ${ }^{3031}$ In contrast to the apparent positivity of the mucicarmine technique reported in recent papers, ${ }^{3-68-121415171923-25}$ Foster and Levine ${ }^{30}$ and Klinick, ${ }^{31}$ searching for "mucins", failed to show carminophilic material with mucicarmine in their two extensive series of primary thyroid carcinomas.

\section{PROBLEMS OF INTER PRETATION}

Previously published reports ${ }^{1-19}$ have based their claim for "mucin secretion" in primary thyroid tumours, essentially on positive staining with the above histochemical methods. One important fact, however, has largely been ignored. Human thyroglobulin-stored as "colloid" in thyroid follicles-contains different carbohydrates, such as neutral sugar, acetyl hexosamine, sialic acid and fucose, ${ }^{32}$ representing 2 to $4 \%$ by weight of thyroglobulin. The carbohydrates contained in thyroglobulin and colloid, or their breakdown products, could well be responsible for the positive staining observed in the thyroid tumours reported as "mucin secreting" or "mucinous". Two findings favour this hypothesis. Firstly, "mucin production", whether intracellular or extracellular, has generally been described as scarce and scattered in most of these thyroid tumours. ${ }^{1-1923}$ There has been only one instance in which pools of abundant extracellular mucin were noted. ${ }^{3}$ This observation would be in keeping with the known low sugar contents of colloid; an excess of these carbohydrates, however, due to increased tumour cell turnover, could still be envisaged. Secondly, some authors have shown that the "mucinous" material stained by mucin techniques also shows positive immunostaining with thyroglobulin antiserum. ${ }^{111623}$

The above interpretation of "mucin secretion", related to the carbohydrate contents of thyroglobulin and colloid, could understandably apply to thyroid tumours of follicular origin. But what about cases of "mucin producing" medullary carcinoma? It has been increasingly recognised that thyroglobulin immunoreaction can be observed in medullary carcinoma, and several cases of so called "mixed medullary follicular thyroid carcinoma" have now been reported. ${ }^{33-36}$ The origin of this thyroglobulin immunoreaction in medullary carcinoma, however, is yet unresolved: direct synthesis ${ }^{3436}$ or phagocytosis $^{3335}$ of thyroglobulin by neoplastic C cells. When reviewing those previously published cases of "mucin producing" medullary carcinoma, which were also studied by immu- 
nohistochemistry, ${ }^{6-8}$ it is somewhat surprising to realise that only calcitonin immunostaining had been performed and that thyroglobulin had apparently not been tested.

Conventional electron microscopy has also been performed in a few instances of "mucin secreting" or "mucinous" primary thyroid tumours. ${ }^{5-71213}$ The interpretation of the ultrastructural nature of intracytoplasmic "mucinous" material, however, has often been based on the assumption that prior histochemical methods had identified mucins as such. The possibility that "clear vesicles", 5 "mucus granules", 6 "mucin like vacuoles", "mucin like droplets"12 and "vesicles of mucus"13 could actually represent thyroglobulin or colloid has not been fully entertained in these electron microscopic studies.

In our present study 40 cases of primary carcinomas of the thyroid (papillary, follicular, anaplastic, and medullary) were stained with AB/PAS and HID/AB, according to a strict methodology. The positive pure and mixed alcianophilia observed in $7.5 \%$ and about $50 \%$, respectively, of our material could be interpreted as representing genuine mixtures of acidic and neutral "mucin". The histogenesis of such genuine "mucin secretion" in thyroid tumours, however, remains difficult to explain. Of course, dual differentiation-that is, combination of mucin secretion and endocrine function - could be envisaged for these unusual thyroid neoplasms. ${ }^{1116}$ Certainly, it is conceivable that neoplastic follicular and parafollicular cells of the thyroid could undergo dual differentiation like other endodermally derived neoplasms (lung, pancreas, or gastrointestinal tract). ${ }^{11}$

Nevertheless, because of existing problems of methodology and interpretation, we feel that the evidence published so far to substantiate the concept of genuine "mucin secreting" or "mucinous" primary thyroid tumours is not entirely convincing. This evidence is therefore also insufficient for comparing these thyroid tumours with conventional mucin secreting neoplasms derived from gastrointestinal or bronchial origin. Carbohydrates contained in thyroglobulin or colloid could well be responsible for the apparent "positive" staining obtained with the conventional histochemical methods for mucins, and this could apply to thyroid tumours of both follicular and $\mathbf{C}$ cell origin.

\section{Addendum}

Since this paper was accepted for publication, two additional cases of signet ring cell "mucinous" adenomas of the thyroid have been described. ${ }^{37}$ The author used 18 different histochemical methods (some producing overlapping results), coupled with thyroglobulin immunostaining, and his overall conclusion lends support to our present study.
We thank Mrs MJ Bianchi for secretarial assistance, and Mrs MG Durand and Mrs B Didier for technical assistance. We are also grateful to Dr MI Filipe (London) for reading the manuscript and for valuable comments.

\section{References}

1 Williams ED, Brown CL, Doniach I. Pathological and clinical findings in a series of 67 cases of medullary carcinoma of the thyroid. J Clin Pathol 1966;19:103-13.

2 Milhaud G, Calmettes C, Dreyfuss G, Mouktar MS. An unusual trabecular thyroid cancer producing calcitonin. Experientia 1970;26:1381-3.

3 Diaz-Perez R, Quiroz H, Nishiyama RH. Primary mucinous adenocarcinoma of the thyroid gland. Cancer 1976;38:1323-5.

4 Rhatigan RM, Roque JL, Bucher RL. Mucoepidermoid carcinoma of the thyroid gland. Cancer 1977;39:210-14.

5 Deligdish L, Subhani Z, Gordon RE. Primary mucinous carcinoma of the thyroid. Report of a case and ultrastructural study. Cancer 1980;45:2564-7.

6 Fernandes BJ, Bedard YC, Rosen I. Mucus-producing medullary cell carcinoma of the thyroid gland. Am J Clin Pathol 1982;78:536-40.

7 Martinelli G, Bazzochi F, Govoni E, Santini D. Anaplastic type of medullary thyroid carcinoma. An ultrastructural and immunohistochemical study. Virchows Arch (Pathol Anat) 1983;400:61-7.

8 Zaatari GS, Saigo PE, Huvos AG. Mucin production in medullary carcinoma of the thyroid. Arch Pathol Lab Med 1983;107:70-4.

9 Civantos F, Albores-Saavedra J, Nadji M, Morales AR. Clear cell variant of thyroid carcinoma. Am J Surg Pathol 1984;8:187-92.

10 Fransilla KO, Harach HR, Wasenius VM. Mucoepidermoid carcinoma of the thyroid. Histopathology 1984;8:847-60.

11 Mendelsohn G. Signet-cell-simulating microfollicular adenoma of the thyroid. Am J Surg Pathol 1984;8:705-8.

12 Mizukami Y, Matsubara F, Hashimoto T, et al. Primary mucoepidermoid carcinoma in the thyroid gland. A case report including an ultrastructural and biochemical study. Cancer 1984;53:1741-5.

13 Golouh R, Us-Krasovec M, Auerspers M, Jancar J, Bondi A, Eusebi V. Amphircine-composite calcitonin and mucinproducing - carcinoma of the thyroid. Ultrastruct Pathol 1985;8:197-206.

14 Harach RH. A study on the relationship between solid cell nests and mucoepidermoid carcinoma of the thyroid. Histopathology 1985;9:195-207.

15 Mlynek ML, Richter HJ, Leder LD. Mucin in carcinomas of the thyroid. Cancer 1985;56:2647-50.

16 Rigaud C, Peltier F, Bogomoletz WV. Mucin producing microfollicular adenoma of the thyroid. J Clin Pathol 1985;38:277-80.

17 Sobrinho-Simoes M, Nesland JM, Johannessen JV. A mucinproducing tumour in the thyroid gland. Ultrastruct Pathol 1985;9:277-81.

18 Uribe M, Fenoglio-Preiser CM. Medullary carcinoma of the thyroid gland. Clinical, pathological and immunohistochemical features with review of the literature. Am J Surg Pathol 1985;9:577-94.

19 Sobrinho-Simoes M, Stenwig AE, Nesland JM, Holm R, Johannessen JV. A mucinous carcinoma of the thyroid. Path Res Pract 1986;181:464-9.

20 Meissner WA, Warren S. Tumours of the thyroid gland. 2nd series. Washington, DC: Armed Forces Institute of Pathology, 1968.

21 Hedinger C. Histological typing of thyroid tumours. Geneva: World Health Organisation, 1974. 
22 Filipe MI, Lake BD. Histochemistry in pathology. Edinburgh: Churchill Livingstone, 1983:310-3.

23 Carcangiu ML, Sibley RK, Rosai J. Clear cell change in primary thyroid tumors. A study of 38 cases. Am J Surg Pathol 1985;9:705-22.

24 Dayal Y, Uccik AA, Safaii H, Pohl D. Thyroglobulin and clearcell tumors. Am J Surg Pathol 1986;10:70-2.

25 Schröder S, Böcker W. Signet-ring-cell thyroid tumors. Follicle cell tumors with arrest of folliculogenesis. Am J Surg Pathol 1985;9:619-29.

26 Carlstedt I, Sheehan JK, Corfield AP, Gallagher JT. Mucous glycoproteins: a gel of a problem. Essays in Biochemistry 1985;20:40-76.

27 Laboisse CL. Structure of gastrointestinal mucins: searching for the Rosetta stone. Biochimie 1986;68:611-7.

28 Cook HC. Carbohydrates. In: Bancroft JD, Stevens A, eds. Theory and practice of histological techniques, 2nd ed. Edinburgh: Churchill Livingstone, 1982:180-216.

29 Drury RAB, Wallington EA. Carbohydrates and mucosubstances. In: Carleton's histological technique. 5th ed. Oxford: Oxford University Press, 1980:232-59.

30 Foster EA, Levine AJ. Mucin production in metastatic carcinoma. Cancer 1963;10:506-9.

31 Klinck GH. Structure of the thyroid gland. In: Hazard JB, Smith DE, eds. The thyroid. Baltimore: Williams \& Wilkins,
1964:9.

32 Fasman GD. Handbook of biochemistry and molecular biology. 3rd ed. Proteins. Vol II. Cleveland: CRC Press, 1976:271-3.

33 DeLellis RA, Moore FM, Wolfe HJ. Thyroglobulin immunoreactivity in human medullary carcinoma. Lab Invest 1983;48:20A.

34 Uribe M, Fenoglio-Preiser CM, Grimes M, Feind C. Medullary carcinoma of the thyroid gland. Clinical, pathological, and immunohistochemical features with review of the literature. Am J Surg Pathol 1985;9:577-94.

35 Perrone T. Mixed medullary-follicular thyroid carcinoma. Am J Surg Pathol 1986;10:362-3.

36 Holm R, Sobrinho-Simoes M, Nesland M, Johannessen JV. Concurrent production of calcitonin and thyroglobulin in the same neoplastic cells. Ultrastruct Pathol 1986;10:241-8.

37 Gherardi G. Signet ring cell "mucinous" thyroid adenoma: a follicle cell tumour with abnormal accumulation of thyroglobulin and a peculiar histochemical profile. Histopathology 1987;11:317-26.

Requests for reprints: Dr C Rigaud, Laboratoire d'Anatomie Pathologique, Institut Jean Godinot, BP 171, 51056 Reims Cedex, France. 